\title{
Ludwig von Mises: as Bases de sua Epistemologia e uma Proposta de Crítica Internalista
}

\author{
Ludwig von Mises: the basis of his Epistemology \\ and an internalist critical proposal
}

RICARDO FEIJO*

\begin{abstract}
RESUMO: O argumento central do artigo é que boas críticas à epistemologia de von Mises devem considerar os conceitos e a interpretação do mundo assumindo sua própria base filosófica e que só podemos tentar refutá-la mostrando alguma inconsistência ou fraqueza em suas suposições. Para esta tarefa, no início, mostramos Mises ao público leigo e explicamos detalhadamente seu conteúdo epistemológico. No final, escrevemos sobre a irrelevância de algumas refutações críticas e damos exemplos de boas críticas internas.

PALAVRAS-CHAVE: História do pensamento econômico; Mises; Escola Austríaca; praxeologia.
\end{abstract}

ABSTRACT: The paper's central argument is that good criticism to von Mises' epistemology must consider the concepts and world interpretation assuming his own philosophical ground and that we can only try to refute it by showing some inconsistency or weakness in its presumptions. For this task, at beginning we show Mises to layman public, and we explain with detail his epistemological content. In the end we write about the irrelevance of some critical refutations, and we give examples of good internal criticism.

KEYWORDS: History of economic thought; Mises; Austrian School; praxeology.

JEL Classification: B25; B31.

\section{INTRODUÇÃO}

Ludwig von Mises nasceu no dia 29 de setembro de 1881 na cidade de Lemberg, então parte do Império Austro-Húngaro. $\mathrm{Na}$ virada do século, ingressou na Universidade de Viena, cidade em que fora criado, para doutorar-se em direito e economia em 1906. Na companhia de outros jovens talentos, entre eles Joseph Schumpeter, Mises integrava o grupo que se reunia para ouvir os seminários de

\footnotetext{
* Professor Assistente Doutor da Faculdade de Economia e Administração da Universidade de São Paulo — FEA/USP, campus de Ribeirão Preto, e-mail riccfeij@usp.br.
} 
BohmBawerk, o grande mestre da assim chamada Escola Austríaca de Economia. Em pouco tempo ele se projetou como um dos mais aplicados alunos de BohmBawerk, embora Mises, por essa época, tenha percebido importantes lacunas no pensamento austríaco. ${ }^{1}$ As preleções de Bawerk repetiam-se periodicamente até o seu falecimento, no ano de 1914. A partir de então, as atenções se voltaram para as ideias de Mises e de estudantes mais jovens que, por essa época, iniciavam seus primeiros trabalhos, entre eles F. A. Hayek. ${ }^{2}$

Nos anos 20 e 30, as discussões econômicas entre os pensadores austríacos concentram-se mais no ambiente fora da universidade. Na Câmara do Comércio de Viena, Mises organizou os seus famosos seminários (em alemão Privatseminars), que reuniam economistas, sociólogos e cientistas políticos ${ }^{3}$ onde se expunha as deficiências por ele detectadas na teoria bawerkiana. A principal delas incidia na análise da moeda, tema de que se ocupou na sua primeira grande obra, Teoria da Moeda e do Crédito, publicada em 1912, em que apresenta também os rudimentos de sua teoria do ciclo econômico. ${ }^{4}$ No ano seguinte ao da publicação do livro, ele se tornou professor de economia na Universidade de Viena e ao longo da década de 20 projetou-se com os seus seminários. No entanto, Mises não era por essa época muito conhecido fora da Áustria e o seu livro só foi traduzido para o inglês em 1934. Na própria Áustria, a Escola Austríaca entrara num pronunciado declínio após a saída de cena de Bohm-Bawerk.

O economista neo-austríaco M. Rothbard descreve que, por essa época, os economistas austríacos ortodoxos teceram fortes críticas às ideias de Mises e ao modo como ele tinha incorporado a moeda e o ciclo econômico à análise austríaca. Mises sentiu então que seria necessário criar uma nova Escola Austríaca e começa a trabalhar na criação de uma base epistemológica apropriada à sua visão da ciência econômica, exposta primeiramente em Die Grund probleme der Nationalokonomie, lançado em 1933 e traduzido para o inglês apenas em 1960, sob o título Epistemological Problems of Economics. ${ }^{5}$ Mises torna-se um importante crítico da intervenção estatal e passa a ser visto como um paladino da economia de mercado.

As ideias epistemológicas de Mises foram introduzidas na Inglaterra, sob forma algo diluída, por seu aluno Lionel Robbins, economista inglês que extraiu da at-

\footnotetext{
${ }^{1}$ Rothbard (1988, p. 19) comenta:”... imbuído da abordagem austríaca, Mises chegou à conclusão de que Bohm-Bawerk e seus predecessores não tinham avançado o suficiente: não tinham levado sua análise tão longe quanto era possível, e, em consequência, restavam ainda importantes lacunas na teoria econômica da Escola Austríaca”.

${ }^{2}$ Cf. Kirzner (1987, pp. 145-50). Hayek (1 968, pp. 460-1) diz que antes da Primeira Grande Guerra a fama da Escola Austríaca deve-se aos ensaios de Böhm-Bawerk, Wieser e Philippovich. Hayek também destaca a importância dos seminários de Böhm-Bawerk na formação dos membros da terceira geração dessa escola.

${ }^{3}$ Entre eles Felix Kaufmann, A. Schütz e Erik Voogelin.

${ }^{4}$ No original em alemão, Theorie des Geldes und der Umlaufsmitel.

${ }^{5}$ Mises (1933).
} 
mosfera intelectual de Viena o seu famoso livro An Essay on the Nature and Significance of Economic Theory, através do qual um número de ideias austríacas foi absorvido pelo mainstream da literatura econômica anglo-americana. Robbins também ajudou a divulgar as ideias austríacas quando convidou Hayek, em 1931, a assumir uma cadeira na London School of Economics. A entrada de Hayek na cena britânica contribuiu em muito para a divulgação da teoria austríaca dos ciclos econômicos, já esquematizada por Mises em 1912, que atribui a fase de boom do ciclo à má alocação intertemporal estimulada por taxas de juros muito baixas e a fase de baixa do ciclo ao abandono de projetos insustentáveis. Na década de trinta, tal teoria seria bem aceita, porém seu triunfo teve vida curta, tendo sido duramente criticada.

A Segunda Guerra Mundial dispersou os últimos grandes economistas que ainda residiam em Viena. ${ }^{6}$ A própria idéia de uma Escola Austríaca distinta da ortodoxia principal perdera sentido por essa época. Muitos acreditaram que as importantes contribuições austríacas tinham sido com sucesso absorvidas pelo mainstream da teoria econômica. No entanto, desde os anos 20 Mises procurou edificar os fundamentos filosóficos de sua visão, apontando as diferenças que demarcam a teoria austríaca da microeconomia tradicional. Mises continuou esse trabalho fora da Áustria, vindo a estabelecer-se na Universidade de Nova York. Hayek também viria a emigrar para os Estados Unidos, tornando-se professor em Chicago.

Os anos 20 representam o momento em que os austríacos da terceira e quarta gerações iriam reafirmar a especificidade de sua tradição de pensamento em contraste à escola de Alfred Marshall e a tradição do equilíbrio geral. ${ }^{7}$ Trata-se da retomada das teses austríacas na teoria econômica, principalmente com os ensaios de von Mises. O desenvolvimento de novas ideias acompanharia a controvérsia teórica em torno da viabilidade econômica do socialismo, presente no "Debate do Cálculo Socialista". ${ }^{8}$ Mises ataca as teses dos socialistas alemães que se apoiavam nas conclusões do modelo de controle centralizado baseado na análise walrasiana

\footnotetext{
${ }^{6}$ Sobre o ambiente intelectual em Viena nos "anos loucos" que precederam a segunda grande guerra e a diáspora dos economistas austríacos, vide Craver (1986).

${ }^{7}$ Hayek é da quarta geração da Escola Austríaca, que começou a se destacar a partir de 1920; também fazem parte dela Gottfried Haberler, Fritz Machlup, Alexander Mahr, Oskar Morgenstern e Paul N. Rosenstein. Mises considerava a construção do equilíbrio uma ferramenta indispensável para a economia e para a nossa compreensão dos eventos do mundo real, mesmo que as condições de equilíbrio não se verificassem nos mercados. Ele não nega que as técnicas matemáticas possam ser usadas para se descrever posições de equilíbrio, mas este não é o fim da economia, já que essa ciência busca entender os processos de mercado pela explicação causal; importa a ela a descrição de um estado e sua transformação em outro estado. A explicação econômica deve se preocupar em descrever a convergência ao equilíbrio e para tanto a matemática não serve ao modelo miseano, conforme nos lembra White (19 77 , p. 21).

${ }^{8}$ Keizer (1989, p. 65) identifica três controvérsias: duas envolvendo Mises, contra os marxistas da Europa Central, entusiastas do modelo de Barone, e contra os teóricos do "socialismo de mercado " que se seguiram. A outra controvérsia envolve Hayek e estes últimos.
} 
de equilíbrio geral desenvolvido pelo economista italiano Enrico Barone. ${ }^{9}$ Em sua obra de 1922 Socialismo: uma Análise Econômica e Sociológica, Mises critica as teses socialistas utilizando-se de uma nova perspectiva calcada no subjetivismo e delineia a "praxeologia" ou ciência da ação humana, assim chamada como uma estratégia de redefinição crítica do âmbito da ciência econômica. O estudo da ação humana, na ótica de Mises, seria necessariamente a priori, partindo de axiomas considerados não meras hipóteses de partida, mas proposições apodíticamente corretas. Toda a análise subsequente decorre logicamente desses pressupostos, como uma necessidade lógica. É o nascimento da sua epistemologia "racionalista". ${ }^{10}$

$\mathrm{O}$ apriorismo e o subjetivismo eram os traços metodológicos principais da crítica de Mises. ${ }^{11} \mathrm{Na}$ obra de 1922, ele procurou demonstrar a impossibilidade do cálculo racional no socialismo. Argumenta que os termos empregados pela teoria walrasiana, como os de equilíbrio, competição, conhecimento, custo e até mesmo cálculo racional, possuem um significado próprio quando pensados para uma economia capitalista, diferente do significado atribuído a eles quando interpretados à luz de uma economia centralizada que havia sido examinada teoricamente no ensaio de Barone. Mises acusa a teoria de Barone por incorporar uma noção de equilíbrio walrasiano essencialmente estática e dessa forma não desenvolver adequadamente uma perspectiva do processo de mercado. Considera então que o entendimento do capitalismo como uma dinâmica seria fundamental para a sua compreensão teórica, pois os mercados estão sempre em uma situação de desequilíbrio, provocada a cada momento pelas mudanças contínuas nos parâmetros. Os agentes econômicos não têm certeza com relação ao futuro, e no processo de mercado, face à intensa rivalidade entre eles, informações específicas são, a cada período,

\footnotetext{
${ }^{9} \mathrm{O}$ paradigma hegemônico do equilíbrio geral walrasiano foi aplicado à economia socialista pela primeira vez por Enrico Barone (s.d., pp. 245-289) no seu artigo "The Ministry of Prodution in the Collectivist State", originalmente publicado em italiano na revista II Giornale degli Economisti, em 1908. Utilizando o critério de otimalidade de Pareto, Barone acreditou provar que uma economia controlada poderia atingir uma alocação eficiente de recursos. Hutchison (195 3, p. 214) conta-nos que Barone não era favorável ao socialismo e estava interessado simplesmente em demonstrar uma possibilidade teórica. A obra de Barone teve instantaneamente grande acolhida por parte dos colegas socialistas, principalmente alemães. $\mathrm{Na}$ opinião deles, Barone teria demonstrado que o vetor de equilíbrio calculado pelo modelo walrasiano de interdependência geral dos mercados poderia ser estabelecido na prática, de modo a forçar a economia a trabalhar, desde o início, num ponto de eficiência, sem os desgastantes processos de equilibração que se observam nos mercados competitivos. É possível, portanto, operar eficientemente uma economia planejada através de um cálculo racional. A receita de Barone consiste em ajustar os preços de modo a aproximar a economia real do equilíbrio teórico.

${ }^{10}$ Identificamos o subjetivismo de Mises como "racionalista" porque sua epistemologia acredita que o conhecimento pode ser alcançado pela análise de conceitos, de modo independente da experiência empírica com o mundo à nossa volta. A ideia de caracteriza-lo desta forma surgiu a partir da leitura de Parsons (1990) especialmente na página 310.

${ }^{11}$ Kirzner (1986, p. 34) considera que o subjetivismo não havia adquirido uma existência completamente articulada em Menger. Para Kirzner, Mises e Hayek viriam a aprofundar o subjetivismo a partir dos anos vinte.
} 
comunicadas pelo sistema de preços. As informações transmitidas pelos preços seriam um requisito indispensável para o cálculo racional.

Mises assevera que o mercado operando livremente e as demais instituições do capitalismo são condições essenciais para o cálculo econômico. Em outras palavras, a alocação de recursos somente pode ser racionalmente direcionada na presença de um sistema de preços flexíveis. Portanto, a crítica de Mises ao cálculo socialista não é só de ordem prática mas também teórica: o cálculo econômico racional para ele é teoricamente impossível sem a presença de certas instituições do capitalismo tais como moeda, preços flexíveis, mercados para os produtos intermediários e propriedade privada. Já o modelo de Barone não leva em conta instituições sociais específicas, e na determinação da alocação ótima no socialismo pretende ser neutro em relação às instituições sociais. $\mathrm{O}$ economista italiano trabalha com preços, moeda e mercados sob a hipótese de que esses "instrumentos" operam igualmente bem em qualquer sistema econômico. Mises ataca a hipótese de "instrumentos neutros" de Barone, uma vez que os mecanismos econômicos não operariam da mesma forma em qualquer sistema econômico. Para o austríaco, tais mecanismos só funcionam bem na presença da propriedade privada e de outras instituições capitalistas. ${ }^{12}$

$\mathrm{Na}$ Controvérsia Socialista, o nome de Mises tornou-se amplamente conhecido pela sua crítica ampla e robusta ao socialismo. O seu esforço intelectual merece elogios, mas não vamos nos ocupar diretamente com o conteúdo dessa crítica, pois buscamos enfatizar apenas os argumentos metodológicos e epistemológicos de Mises que se desenvolveram por essa época e que serão apresentados na próxima seção. Além disso, os principais pontos levantados por ele sobre a impossibilidade de alocação racional no socialismo não são muito originais. É também a opinião de Hutchison (1981, p. 208), onde ele aponta que os argumentos principais de Mises, nesse tocante, já haviam sido levantados décadas atrás pela escola histórica alemã e em autores do "Verein für Sozialpolitik" (Nasse, Lujo Brentano e especialmente Schaeffle). ${ }^{13}$

A projeção de Mises também esteve associada a aspectos de sua teoria econômica técnica, especialmente às suas teorias da moeda, do capital, da competição e dos ciclos econômicos. ${ }^{14} \mathrm{~A}$ sua epistemologia teve uma certa ascendência em Lon-

\footnotetext{
${ }^{12} \mathrm{O}$ modelo de Barone não leva em conta instituições sociais específicas. Pelo contrário, na determinação da alocação ótima no socialismo pretende ser neutro em relação às instituições. Admite a existência de moeda, preços, juros e demais instrumentos típicos de uma economia de mercado, atribuindo-lhes o mesmo significado tradicional. $\mathrm{O}$ modelo exclui, no entanto, a propriedade privada, o mercado de capitais e o mercado de insumos, o que o caracteriza como um modelo "socialista de mercado". Keizer (1989, pp. 68-69) nos conta que Barone trabalha com preços, moeda e mercados, admitindo que esses instrumentos operam igualmente bem em qualquer sistema econômico, hipótese conhecida como "instrumentos neutros".

${ }^{13}$ Brentano foi membro fundador do "Verein für Sozialpolitik", literalmente "Sociedade para a Política Social", permanecendo nela até 1929 , quando o Verein tinha se transformado em um movimento reacionário. Brentano considerava a desigualdade social necessária.

${ }^{14}$ Schumpeter admirava o Theory of Money and Credit. Kirzner (1981, p. 18) identifica uma retomada de interesse, nos dias atuais, por estas contribuições teóricas.
} 
dres nos anos 30 e veio a conhecer um ressurgimento de popularidade em nossos dias, principalmente entre os seus discípulos norte-americanos ligados à escola neoaustríaca e entre apologistas modernos do liberalismo. De fato, Mises tornou-se amplamente conhecido como um defensor fervoroso do livre mercado. Suas teses nesse sentido são muito citadas por aqueles que se encontram neste ponto do espectro ideológico.

Pretendemos neste artigo examinar criticamente os principais pontos da epistemologia de Mises, mostrando:

- As crenças básicas da praxeologia e sua rejeição ao método histórico.

- A inadequação de certas críticas feitas à praxeologia.

Concluiremos o artigo com algumas propostas de críticas pertinentes a essa epistemologia.

\section{A TEORIA DA AÇÃO HUMANA E A CRÍTICA AO HISTORICISMO}

Nesta seção, iremos investigar a natureza da epistemologia de Mises a que chamamos "racionalista". O primeiro passo nesse sentido é a constatação da visão básica da sociedade e dos processos econômicos em Mises. Mises considera a sociedade como uma ordem harmônica, mas a estrutura social não é pensada como uma totalidade orgânica e natural tal qual encontramos em Carl Menger, o pai da Escola Austríaca. ${ }^{15}$ De fato, Mises compõe a sua perspectiva da sociedade em outras bases. Na literatura secundária sobre ele, alguns comentadores têm interpretado a sua visão de ordem harmônica como uma herança do filósofo Leibniz. ${ }^{16}$

$\mathrm{Na}$ ótica de Mises, não há, como em Menger, uma estrutura de elementos essenciais e eternos que comandem o funcionamento da vida econômica, tais como necessidades, bens e satisfação, e que são tidos como naturais. A sociedade é decorrência de um processo de desenvolvimento histórico e como tal deve ser estudada pela história, no entanto Mises nega que o historicismo possa por si só entendê-la em seus aspectos básicos e acredita que o estudo histórico deve ser precedido pela investigação teórica. Neste ponto, ele segue Menger ao separar teoria pura e história, mas ele se vale de argumentos diferenciados. Mises também acompanha o método introspectivo e a preocupação com o conhecimento subjetivo presentes em Menger, mas ao que parece esses aspectos epistemológicos não foram recebidos diretamente de Menger e sim a partir das influências de Weber e dos filósofos neokantianos. ${ }^{17}$

\footnotetext{
${ }^{15}$ Sobre a visão naturalista de sociedade em Menger, vide Menger (1883).

16 Por exemplo, em Johnston (1983, p. 86): "For the invisible hand of Adam Smith, the economists substituted a Leibnizian premise of harmony between created nature and social law" - e Parsons (1990 p. 196, nota de rodapé 5): “... there is some truth in this suggestion of indebtedness to Leibniz..."

${ }^{17}$ Não se deve exagerar a proximidade entre Mises e Weber, como na afirmação de Lachmann, citada em White (1977, p. 26), que diz que na obra Ação Humana " it is the work of Max Weber that is being
} 
Os filósofos neokantianos, principalmente os da Escola de Baden, tais como Windelband e Rickert, centralizavam em suas reflexões a questão da possibilidade de uma compreensão objetiva da história. ${ }^{18}$ Eles não acreditavam que a descrição dos processos históricos pela teoria poderia ser tida como verdadeira (no sentido kantiano de verdade como correspondência entre conceitos categóricos e fenômenos empíricos). Os neokantianos substituem o conceito de verdade apodítica pela noção de validade. Então o discurso histórico precisa ser validado objetivamente e eles apelam para o senso comum como um meio de garantir a validade da descrição histórica. ${ }^{19}$ Os neokantianos não apontavam para a necessidade de uma interpretação teórica que deveria preceder a análise histórica e foram tidos por Mises como historicistas. ${ }^{20}$

Mises apoia-se no método introspectivo como uma garantia da verdade $a$ priori de seus postulados teóricos. A teoria científica deve ser utilizada pelo historiador como uma ferramenta de análise que dita os conceitos e categorias que irão decifrar o significado concreto dos eventos históricos. Portanto, a teoria precede a história e assenta-se numa base que independe dela. O historicismo busca leis empíricas nas ocorrências dos fenômenos históricos que descrevem as regularidades do processo social como um todo, mas Mises não aceita a ideia de regularidades na totalidade social. Ele acha que apenas na observação de fenômenos individuais dentro da sociedade podemos identificar regularidades. Há portanto no evento social específico elementos permanentes que devem ser apreendidos não apenas pela observação mas principalmente pela teoria. A história e a teoria unem-se na explicação do fenômeno básico da vida social que é o indivíduo efetuando escolhas entre diferentes cursos de ação face à sua subjetividade.

Então a concepção básica da investigação social em Mises parte do "individua lismo metodológico" também presente em Menger, mas que nele adquire outros contornos epistemológicos. O individualismo metodológico também foi inspirado na estratégia neokantiana. Para Mises, a análise teórica dos processos sociais só deve considerar as ações individuais. Conjuntos coletivos como nações, partidos e outras instituições sociais, embora sejam reconhecidamente entidades sociais reais,

carried on here". Não devemos esquecer que nesta mesma obra (1949, p. 126) Mises tece críticas a Weber: "Max Weber, it is true, was not sufficiently familiar with economics and was too much under the sway of historicism to get a correct insight into the fundamentals of economic thought".

18 "Parsons (1990, pp. 298-300) separa didaticamente o movimento neokantiano em duas escolas: a de Marburg, representada por Cohen, Natorp e Cassirer, e a Escola de Baden, representada por Windelband e Rickert.

${ }^{19}$ Parsons (1990) explica que o conceito kantiano de verdade diz respeito ao acordo do conhecimento com o objeto, mas a noção de "validade" é independente da existência de um objeto. Explica também que a validação ocorre quando identificamos valores absolutos, que para Windelband se encontram no estado de "consciência normal ".

2020 Mises (1933, p. 5): "Windelband, Rickert, and their school... are weakened by their failure to conceive of the possibility of universally valid knowledge in the sphere of human action... they remain bound to historicism". 
não negam o individualismo metodológico, pois o conjunto social opera por intermédio de um ou mais indivíduos que são as únicas entidades que realizam ações. Sendo assim, acredita Mises que se investigarmos o significado dessas ações aprenderemos tudo sobre as ações do conjunto. ${ }^{21}$

O núcleo central da investigação teórica é portanto a ação humana individual, e Mises denomina a sua ciência de "praxeologia". A ciência da ação humana permite a coexistência de dois ramos: o estudo histórico e a teoria. ${ }^{22}$ História e análise econômica se relacionam entre si de modo que a compreensão da ação individual concreta requer essas duas vias de abordagem.

A teoria é um agrupamento de conceitos categóricos que se desdobram logicamente em outros conceitos. ${ }^{23} \mathrm{~A}$ partir da identificação lógica dos predicados derivados de conceitos, o conjunto das proposições teóricas é estabelecido. ${ }^{24}$ Há condições categóricas para a ação que são obtidas pela introspecção e outras condições que são estabelecidas pelos estudos dos casos concretos fornecidos pela história. No entanto, é preciso enfatizar que na praxeologia de Mises o núcleo teórico é composto por proposições derivadas de conceitos a priori e pela razão que permite ao investigador identificar todos as decorrências lógicas dos conceitos. A própria lógica em si mesma é universal e eterna, não estando ela mesma sujeita às contingências históricas. E refere-se não apenas à lógica que obedece a teoria, mas também a própria estrutura lógica da mente do ator é estável ao longo do tempo. Mises acredita que as relações lógicas fundamentais da mente humana não poderiam ser diferentes do que são e que nenhum ensinamento da antropologia e da história contradiria essa crença. ${ }^{25}$

A descrição anterior da praxeologia permite caracterizar a epistemologia miseana como sendo "racionalista". O núcleo teórico não está sujeito a vicissitudes históricas, pois é anterior à história e serve como ferramenta para a investigação das ocorrências concretas da ação humana. Mas a ação em si mesma se processa obedecendo aos preceitos lógicos estabelecidos na praxeologia. O indivíduo age apenas com base na sua subjetividade e sendo assim ele faz o que quiser. Mas a teoria da ação só se preocupa com o comportamento voltado à perseguição de fins,

\footnotetext{
${ }^{21}$ Cf. Mises (1949, p. 42).

${ }^{22}$ Pode-se falar em praxeologia histórica e teórica.

${ }^{23}$ Mises (1933, p. 22, nota de rodapé 13) afirma que, não por acaso, diversos grandes economistas eram também grandes lógicos; cita Hume, Whately, J. S. Mill e Jevons.

${ }^{24}$ A praxeologia de Mises não parte de proposições tidas como certas, mas de conceitos válidos. O exercício lógico da praxeologia consiste em deduzir tudo o que o conceito já contém. Ela identifica todos os atributos inerentes a um conceito. Este tipo de lógica, que não se confunde com a lógica matemática, é na verdade uma preocupação com análise de significados. Barrota (1996, p. 52) denomina-a " lógica de atribuição de predicados".

25 Cf. Mises (1949, pp. 36-38). Mises (1933, p. 27) afirma: "If thinking and action were really conditioned by place, time, race, nationality, climate, class, etc., then it would be impossible for a German of the twentieth century to understand anything of the logic and action of a Greek of the age of Pericles".
} 
e estabelece as condições categóricas para o seu sucesso. A teoria não precisa corresponder aos fenômenos, ela apenas representa-os considerando indivíduos que agem guiados pela razão. Mises imagina que a lógica universal identificada na análise econômica também deve se fazer presente na ação concreta, pois a lógica é apenas uma, condicionando a consideração teórica da ação e a ação em si mesma quando pensada pelo agente. Desvios do comportamento racional podem ser observados, mas isto é tarefa da análise histórica. A praxeologia só considera a ação racional. ${ }^{26}$

O axioma da racionalidade de toda ação voltada ao alcance de maior satisfação individual é o ponto de partida da análise praxeológica. A ação em Mises é um conceito inseparável da idéia de racionalidade. Mises rejeita todo critério exógeno de definição de racionalidade. Os elementos subjetivos que comandam a ação não podem ser previamente identificados, são as escolhas do agente que demonstram as suas avaliações subjetivas. ${ }^{27}$ Não há uma escala natural de importância dos bens que seja identificada pelo observador antes mesmo da ação e que possa medir o grau de racionalidade da ação. A hipótese de racionalidade é o ponto de partida que permite à teoria identificar os elementos subjetivos que comandam a ação, e sendo assim ação é racional por definição. ${ }^{28}$

Outro axioma básico da praxeologia é o de que toda ação ocorre no tempo, o que mantém em Mises a noção de causalidade temporal presente em Menger. A ação liga-se à existência de causalidade, pois sem ela não haveria como o indivíduo orientar suas ações com vistas ao alcance de objetivos num instante futuro. Quan-

\footnotetext{
${ }^{26}$ A frase "toda ação é racional” quando fora do contexto da praxeologia não seria aceita por Mises. White (1977, p. 16) sintetiza o método praxeológico: "Praxeology, according to Mises, is not concerned with why individuals pursue the specific purposes they do, but only with what can be deduced from the axiom that they do act purposively. From this fundamental axiom of human action, with the aid of certain subsidiary assumptions, the praxeologist deduces the entire body of economic theory".

${ }^{27} \mathrm{~A}$ investigação histórica nos diz se o comportamento é propositado ou não, isto é, diz em que caso temos ação propositada ou outra forma de comportamento humano. Os desvios em relação à ação racional não são determinados pela identificação de discrepâncias entre o comportamento e a estrutura de preferências individuais. Na história, tais desvios são localizados quando o estudioso é capaz de identificar, em bases independentes, outros motivos para o comportamento individual que não o comportamento propositado. Portanto, os desvios não são erros de avaliação gerados por informação incompleta do agente homem.

${ }^{28}$ Hutchison (1981, p. 209) lembra que o axioma da ação racional não depende de hipóteses específicas sobre conhecimento e ignorância, ou sobre a natureza das mudanças das expectativas. Caldwell (1984, p. 366) observa que em Mises o contrário de ação racional não é ação irracional mas ação inconsciente. Mises (1933, pp. 23-24) reconhece que às vezes não é fácil separar ação consciente de comportamento inconsciente. A noção de tempo está intimamente conectada ao pressuposto de ação racional e é por causa do tempo que não podemos concebê-la de outra forma. A passagem do tempo implica em contínua mudança nas estruturas de preferências. Escolhas aparentemente inconsistentes não significam necessariamente irracionalidades se as interpretarmos simplesmente como traduzindo mudanças nas estruturas de preferências. Cf. Mises (1949, p. 103).
} 
do agimos, sempre pensamos na maneira como os meios disponíveis poderiam levar, pela ação da causalidade, aos objetivos pretendidos. ${ }^{29}$

Os dois conceitos básicos anteriores (ação racional e tempo real) permitem à praxeologia deduções teóricas sobre a estrutura lógica que comanda a ação. Também a ação concreta que se observa nos indivíduos em sociedade deve seguir a mesma estrutura lógica, e portanto há uma ponte interligando o fenômeno real da ação ao esquema lógico que a representa na teoria. Mas a teoria não precisa ter uma correspondência com a realidade dos fenômenos e só a experiência permite revelar as condições concretas em que ocorre a ação, porém as categorias lógicas fundamentais que descrevem a ação são $a$ priori à experiência. A teoria define o conceito de bem econômico, mas só a história permite reconhecer as condições concretas em que o bem livre se torna bem econômico. A praxeologia supõe a existência de moeda intermediando as trocas, e o fato empírico da moeda não existir no contexto histórico em que prevalecem as trocas diretas não afeta o significado dos teoremas a priori para a ação. ${ }^{30}$

O estudo praxeológico da ação considera como ponto de partida de sua análise a existência do estado de insatisfação e o comportamento consciente do indivíduo para a remoção desse estado. ${ }^{31}$ As leis econômicas obtidas do esquema de raciocínio a priori não podem ser refutadas pela história, permanecendo válidas sem exceção. A investigação histórica não poderia provar que a estrutura lógica da ação varia em função do contexto concreto, e é a racionalidade atemporal e universal do esquema praxeológico da ação que permite a interpretação de fatos históricos singulares. Mises reconhece que a ação individual está condicionada a hábitos estabelecidos pela tradição e fornecidos pelo ambiente histórico. No entanto, acredita que a praxeologia não se ocupa do conteúdo variável da ação, retendo

\footnotetext{
${ }^{29}$ O princípio da causalidade liga-se estreitamente à ideia de ação. Mises (1933, p. 14) afirma que "As an a priori category the principle of action is on a par with the principle of causality". A existencia de causalidade no mundo em que ocorre a ação é reiterada em Mises (1949, p. 22): "in a world without causality and regularity of phenomena there would be no field for human reasoning and human action. Such a world would be a chaos in which man would be at a loss to find any orientation and guidance."

${ }^{30}$ Para Mises (1933, p. 14), cabe portanto ao método axiomático construir uma praxeologia “... so general that its system would embrace not only all the patterns of action in the world that we actually encounter, but also patterns of action in worlds whose conditions are purely imaginary and do not correspond to any experience. A theory of money would still be meaningful even if throughout history there had never been any indirect exchange ". A experiência tem apenas uma importància heurística para a análise da ação (p. 25): " if there had never been indirect exchange, we would not have been able to conceive of it as a possible form of action and to study it in all its ramifications. But this in no way alters the aprioristic character of our science". A relação entre experiência e apriorismo em Mises é discutida em White (1977, p. 18).

31 Outro pré-requisito universal para a ação humana é a existência de bens econômicos e de relações quantitativas entre eles. Mises (1933, p. 14) escreve: “we are unable to grasp the concept of economic action and of economy without implying in our thought the concept of economic quantity relations and the concept of an economic good".
} 
apenas a sua estrutura categórica. O estudo dos aspectos ambientais da ação humana é tarefa da história. ${ }^{32}$

Em 1933, Mises expõe esses argumentos no Die Grundprobleme. O capítulo inicial ocupa-se em criticar o historicismo mostrando que os conceitos teóricos são logicamente anteriores à compreensão dos eventos históricos singulares e portanto eles funcionam como ferramentas do historiador. É vã a tentativa do historicismo de buscar o significado objetivo da totalidade social no curso da história. Apenas a identificação dos fatores que operam nas escolhas individuais bem-sucedidas permite discernir as regularidades no fenômeno. A realidade histórica é um fenômeno complexo e sendo assim só um sistema de conhecimento apriorístico da ação humana possibilita o reconhecimento de leis na história. ${ }^{33}$

No capítulo 2 desse mesmo livro, Mises argumenta que o conceito da ação humana é obtido introspectivamente e que com ele podemos derivar, pela atribuição lógica de significados, todos os principais conceitos econômicos. Diz em seguida que nem todas as condições categóricas para a ação são obtidas pela introspecção e que algumas delas dependerão de situações específicas. As preferências intertemporais do agente, por exemplo, são de natureza empírica. Mas os elementos empíricos não contrariam a atuação de leis a priori. ${ }^{34}$ Os demais temas que discorremos anteriormente são desenvolvidos em outros capítulos.

Em 1949, Mises retoma e aprofunda as ideias do Die Grundprobleme na sua mais famosa obra, a Ação Humana, onde ele integra metodologia e epistemologia econômicas com teoria técnica. ${ }^{35}$ Começa definindo ação humana e diz que esse conceito pressupõe indivíduos com comportamento propositado que percebem um

\footnotetext{
32 A experiência, no entanto, não descarta ou modifica os teoremas a priori. Vide Mises (1933, pp. 27-28).

33 Para Mises (1933, p. 13), a investigação histórica trata das condições sob as quais ocorre a ação humana no detalhe concreto, já a ciência da ação humana" disregarding the accidental, considers only the essential. Its goals is the comprehension of the universal, and its procedure is formal and axiomatic. It views action and the conditions under which action takes place not in their concrete form, as we encounter them in everyday life, nor in their actual setting, as we view them in each of the scinces of nature and of history, but as formal constructions that enable us to grasp the patterns of human action in their purity". O conhecimento das condições em que concretamente se desenvolve a ação só é possível pela experiência: "Only experience can teach us that there are lions and microbes and that their existence can present definite problems to acting man; and it would be absurd, without experience to indulge in speculations about the existence or non existence of some legendary best".

${ }^{34}$ Mises (1933, p. 25): “... in so far as we take into consideration the action of men who are not indifferent to the passage of time and who therefore economize time because it is important to them whether they attain a desired end sooner or later, we must attribute to their action everything that necessarily follows from the categorial nature of time... Whatever follows necessarily from empirical knowledge -e.g., the propositions of the agio theory of interest - lies outside the scope of empiricism." O caráter empírico do tempo é realçado quando ele diz (pp. 24-25): "The fact that the passage of time is one of the conditions under which action takes place is established empirically and not a priori”. $\mathrm{O}$ tempo é um a priori já que ele está implícito no próprio conceito de ação e é também um elemento empírico como se nota na passagem anterior. Isto não é uma contradição já que Mises, como Kant, aceita conceitos "sintéticos a priori".
}

${ }^{35}$ Mises (1949). 
ambiente para a tomada de decisões, formulam planos e estabelecem fins. ${ }^{36} \mathrm{O}$ plano individual requer o conhecimento das tecnologias e recursos disponíveis e dos sacrifícios envolvidos. A ação é orientada para o futuro e depende apenas dos estados imaginados e projetados das variáveis. Toda ação é um balanço mental de alternativas que são percebidas num mundo de incerteza. O estado futuro que se estabelecerá concretamente pode levar à revisão dos planos se forem constatados erros de previsão. O pré-requisito da ação, continua Mises na Ação Humana, é a busca de uma situação mais satisfatória. A mente imagina um cenário mais propício e a ação procura realizar a situação desejada. Mises identifica três motivos que impelem o homem a agir:

- o reconhecimento do desconforto,

- a imagem de uma situação melhor e

- a expectativa de que o comportamento propositado possa afastar ou pelo menos aliviar o desconforto.

Apenas o próprio agente é capaz de avaliar subjetivamente a eficácia da ação e a praxeologia não se preocupa com a natureza dos objetivos pretendidos, pois ela se preocupa com os meios e não com os fins. ${ }^{37}$

A categoria de ação humana é um juízo "sintético a priori" e portanto ela se coloca frontalmente contra a tradicional separação positivista entre julgamentos analíticos (tautologias a priori) e julgamentos sintéticos (que envolvem experimentação). A concepção de categorias sintéticas a priori e a ênfase na análise de conceitos mostram inequivocamente a raiz kantiana da epistemologia racionalista. ${ }^{38}$ Também quando Mises define a ação racional como verdade apodítica temos um ardil kantiano. Mas não há em Mises a preocupação kantiana de estabelecer a correspondência entre teoria e fenômenos da realidade, o que o afasta de Kant e o aproxima dos neokantianos, que substituem o conceito de verdade apodítica pela noção de validade.

Os axiomas da praxeologia não são um resultado da experiência concreta, o que não significa que os dados empíricos tenham um papel nulo. A teoria é uma construção puramente racional e nesse ponto os fatos não interferem. Mas uma vez obtida, ela deve se aplicar à análise e interpretação de fenômenos empíricos concretos. A teoria praxeológica é uma ferramenta de análise que fornece uma descrição básica dos fenômenos. Os casos em que determinadas situações ocorrem

\footnotetext{
${ }^{36}$ Mises (1949, p. 11): "Human action is purposeful behavior. Or we may say: Action is will put into operation and transformed into an agency, is aiming at ends and goals, is the ego's meaningful response to stimuli and to the conditions of its environment, is a person's conscious adjustment to the state of the universe that determines his life."

${ }^{37}$ A natureza dos objetivos pretendidos é indiferente para a praxeologia uma vez que "Its findings are valid for all kinds of action irrespective of the ends aimed at. It is a science of means, not of ends". Mises (1949, p. 15).

${ }^{38}$ A comparação entre Kant e Mises é feita em Barroca (1996).
} 
são selecionados pela história. ${ }^{39}$ Tais casos podem refutar as conclusões do modelo, revelando inclusive imperfeições teóricas. Entretanto, se não for possível a constatação de erros lógicos na teoria, não podemos duvidar de sua verdade, independentemente do que dizem os fatos. ${ }^{40}$ Neste caso os próprios fatos devem ser questionados. Isto não quer dizer que os fatos históricos não tenham alguma importância na validação de teorias, mas eles não são decisivos, pois a experiência histórica é um fenômeno complexo, de onde não é possível obter argumentos teóricos.

A compreensão categórica permite o acesso de certas condições da ação, outras condições são obtidas pela experiência, e é ela que permite identificar, em cada caso, o alcance da análise praxeológica. Mises acredita que o teste empírico possa e deva ser realizado para avaliar a adequação de certas condições categóricas usadas na construção de leis praxeológicas, pois os fenômenos descritos pela praxeologia também dependem das condições contingentes que fazem com que uma lei teórica, mesmo mantendo sua validade, possa não se aplicar em determinados contextos.

É equivocada portanto a interpretação de que o apriorismo de Mises descarta a avaliação empírica, pois só ela permite assegurar que as leis se aplicam a casos concretos. Vemos portanto que as leis praxeológicas não são descrições de uma realidade subjacente (como as leis exatas do naturalismo de Menger), mas consequências lógicas de certas condições assumidas pela razão. A sociedade não configura uma existência natural independente da teoria e não tem sentido no racionalismo falar de uma correspondência direta da teoria com a estrutura social. A estrutura não pode ser observada e tudo o que pretende a teoria é a sua representação analítica em modelos que tomam o indivíduo e seus propósitos como ponto de partida para a construção de um amplo sistema dedutivo.

Os argumentos epistemológicos de Mises desenvolvidos no Die Grundprobleme e na Ação Humana, além de atacarem o historicismo, também procuram refutar as crenças mantidas por autores de dentro e de fora da Escola Austríaca de que a teoria do valor deveria procurar apoio na psicologia. Mises rejeita os estudos psicológicos que buscam o realismo das proposições assumidas na explicação do valor. ${ }^{41} \mathrm{~A}$ praxeologia toma os conceitos de ação, utilidade, satisfação e outros de

\footnotetext{
${ }^{39}$ Mises (1933, pp. 13-14): “The existence of the external world is given through experience; and if we pursue definite plans, only experience can teach us how we must act vis-à-vis the external world in concrete situations. However, what we know about our action under given conditions is derived not from experience, but from reason. What we know about the fundamental categories of action... is not derived from experience. We conceive all this from within, just as we conceive logical and mathematical truths, a priori, without reference to any experience. Nor could experience ever lead anyone to the knowledge of these things if he did not comprehend them from within himsel."

${ }^{40}$ Mises (1933, p. 30): “so long as a re-examination of the theory uncovers no errors in our thinking, we are not entitled to doubt its truth."

${ }^{41}$ Mises (1949, pp. 11-12): “The field of our science is human action, not the psychological events which result in an action. It is precisely this which distinguishes the general theory of human action, praxeology,
} 
modo puramente formal, descartando qualquer preocupação com o conteúdo psicológico ou fisiológico desses conceitos. ${ }^{42} \mathrm{~A}$ "lei da utilidade marginal decrescente" nada tem de psicológico, significa apenas que o estoque de bens pode ser dividido em diferentes unidades que podem ser arranjadas em ordem decrescente de importância e que os valores marginais são decisivos nas trocas de bens. Mises afirma textualmente que essa lei não tem nada que ver com a "primeira lei de Gossen", com a "doutrina mensura sortis" de Bernoulli e nem com a famosa "lei de WeberFechner" ${ }^{43}$ Para a praxeologia, a lei da utilidade marginal decrescente já se encontra implícita na categoria ação e é simplesmente o reverso da afirmação que diz preferirmos o que nos dá mais satisfação ao que nos dá menos dela. A praxeologia não explica os motivos psicológicos da ação, mas se contenta em descrever as leis lógicas decorrentes de seus axiomas.

O estilo argumentativo da praxeologia é sempre o mesmo. Ela busca demostrar tudo o que está implícito no conceito de ação. ${ }^{44} \mathrm{~A}$ "lei da utilidade marginal de crescente” está implícita, como vimos. Também está a incerteza com relação ao fu turo, pois se o indivíduo pudesse conhecer o futuro não teria que escolher e portanto não agiria. ${ }^{45} \mathrm{~A}$ "lei dos rendimentos decrescentes" também tem uma base $a$ priori no conceito de ação. ${ }^{46}$ Portanto vemos que a caraterística metodológica principal da praxeologia é procurar derivar todos o predicados inerentes a um conceito. Quando Mises fala em lógica ele não se refere à lógica matemática — até porque, como Menger, ele é contra o uso da matemática - mas a esse tipo de "lógica de atribuição de significados".

from psychology. The theme of psychology is the internal events that result or can result in a definite action. The theme of praxeology is action as such."

${ }^{42}$ Mises (1933, p. 3) diz que a praxeologia só lida com a ação e com o que segue da ação, enquanto a psicologia tem por objeto os eventos psíquicos que resultam em ação. Portanto, "Economics begins at the point at which psychology leaves off".

${ }^{43}$ Pelo menos um economista famoso do começo do século acreditava que a lei da utilidade marginal decrescente teria sido obtida da famosa lei psicológica de Weber-Fechner. É o caso de Edgeworth no seu livro Mathematical Psychics. Cf. Viner (1958, pp. 182-183). Há poucas evidências nesse sentido, tudo indica que historicamente não existe relação entre a lei econômica e a lei psicológica similar.

${ }^{44}$ Mises (1933, p. 24): “In grasping this concept we simultaneously grasp the closely correlated concepts of value, wealth, exchange, price, and cost. They are all necessarily implied in the concept of action, and together with them the concepts of valuing, scale of value and importance, scarcity and abundance, advantage and disadvantage, success, profit, and loss."

${ }^{45}$ Mises (1949, p. 105): "That man acts and the future is uncertain are by no means two independent matters. They are only two different modes of establishing one thing."

\footnotetext{
${ }^{46}$ No tocante a ela, Mises (1949, p. 129) também identifica considerações empíricas que deveriam ser investigadas . Cita três questões essencialmente empíricas não respondidas pela lei a priori: "l. Whether or not the optimum dose is the only one that is capable of producing the effect sought. 2 . Whether or not there is a rigid limit above which any increase in the amount of the variable factor is quite useless. 3. Whether the decrease in output brought about by progressive deviation from the optimum and the increase in output brought about by progressive approach to the optimum result in proportional or nonproportional changes in output per unit of the variable factor".
} 
Mises acredita na neutralidade da praxeologia e almeja perseguir a verdade de modo austero e desapaixonado. É possível que sua crença em uma teoria livre de valor tenha se inspirado em Weber. ${ }^{47} \mathrm{Na}$ Ação Humana, Mises afirma que o subjetivismo da teoria, que só considera o juízo feito pelo próprio indivíduo quando ele determina suas escolhas, ajuda a tornar a teoria livre de valor. ${ }^{48}$

Os principais aspectos da epistemologia racionalista de Mises foram discutidos nesta seção, onde procuramos também mostrar as suas filiações intelectuais. $\mathrm{Na}$ próxima seção, veremos algumas críticas usualmente feitas à praxeologia.

\section{CRÍTICAS IRRELEVANTES À PRAXEOLOGIA}

Mises e sua praxeologia ocupam uma posição bastante proeminente nos debates em epistemologia econômica e quase sempre ele é criticado. ${ }^{49}$ É bastante curioso o fato de que uma linha de pensamento tida pela maioria dos comentadores como equivocada, ainda assim apareça de modo tão destacado na literatura. ${ }^{50}$ Por que os comentadores insistem em reavaliá-lo ao invés de simplesmente pôr de lado as contribuições de Mises? Tal fato indica a existência de algo muito interessante nas proposições epistemológicas do austríaco. O estilo literário de Mises é muito provocativo. Não estou me referindo ao ideólogo, sempre disposto a atacar com veemência e até com alguma injustiça as teses contrárias ao liberalismo econômico, mas ao epistemólogo. A praxeologia faz assertivas fortes e deixa no leitor a impressão de incoerência, radicalismo e unilateralidade. Quando ela diz que toda ação é racional pensamos logo: isto não esvazia o conceito de racionalidade? Se toda ação é racional, o erro é impossível?

É completamente inócuo acusar a praxeologia miseana de ser dogmática, ininteligível e não-científica. Essas críticas partem, na maioria das vezes, de uma má compreensão das ideias de Mises ou da ausência de um esforço sincero em desvendar o que realmente ele quis dizer, e neste ponto nos solidarizamos com Mises. ${ }^{51}$

\footnotetext{
${ }^{47}$ Esta é a tese defendida por Kirzner (1981, pp. 14-15). Mises (1949, p. 10) afirma: "It's true that economics is a theoretical science and as such abstains from any judgment of value...”.

${ }^{48}$ Mises (1949, p. 21): “ ... it is in this subjectivism that the objectivity of our science lies. Because it is subjectivistic and takes the value judgments of acting man as ultimate data not open to any further critical examination, it is itself above all strife of parties and factions, it is indifferent to the conflicts of all schools of dogmatism and ethical doctrines, it is free from valuations and preconceived ideas and judgments, it is universally valid and absolutely and plainly human."

${ }^{49}$ Para um sumário destas críticas, vide Caldwell (1 984, pp. 365-370).

${ }^{50}$ Basta dizer que somente nas duas principais revistas internacionais sobre o pensamento econômico, a History of Political Economy e a Economics and Philosophy, constatamos sete artigos específicos sobre Mises: Caldwell (1984 e 1986), Hirsch (1986), Parsons (1990), na primeira revista, e Barrota (1996 e 1998) e Parsons (1997) na segunda.

51 Como escreve Bruce Caldwell (1984 , pp. 368-369), um dos mais respeitáveis estudiosos de metodologia e epistemologia econômica dos últimos anos: "The point is that many of the Misesian
} 
Dizer por exemplo que a proposição “ toda ação é racional” é incompreensível não é uma crítica sustentável. Ao considerá-la, deve-se ter em conta o que está por trás da proposição. Ação é uma categoria teórica, é um conceito dotado de atributos e significados. Sendo assim, para a praxeologia toda ação é racional porque toda ação é por definição propositada e envolve escolhas. Poderíamos argumentar que o comportamento habitual ou normativo não pode ser racional. Mas como o comportamento habitual para Mises envolve escolhas ele também é racional. A irracionalidade só ocorreria se a escolha individual fosse contraditória com a escala subjetiva de valores. Tal situação porém não poderia ocorrer para a praxeologia porque é o ato de escolha que demonstra as preferências do ator. Para ela, só existe escolha racional ou comportamento impulsivo. A escolha racional também pode levar a erros, já que o futuro é incerto e o conhecimento é incompleto.

\section{CONCLUSÃO: A PRAXEOLOGIA CRITICADA DE UM PONTO DE VISTA INTERNALISTA}

O que dissemos na seção anterior não significa que não se possa questionar a relevância e adequação da praxeologia. Mas as únicas críticas que realment e contam são as chamadas críticas internalistas. Este tipo de crítica procura refutar a teoria em questão assumindo as suas próprias bases conceituais e identificando certas contradições internas. Por exemplo, em relação ao axioma da racionalidade de Mises, é melhor criticá-lo aceitando-se a estrutura de princípios metodológicos e as hipóteses da praxeologia. Nessa linha, o filósofo Robert Nozick apresenta duas importantes críticas a esse axioma:

1. Mises diz que o ator sempre prefere o resultado da ação corrente ao que poderia ser obtido se esta ação não fosse implementada. É a ideia de que a ação é o curso de escolhas que procura maximizar algum resultado. Há no entanto o problema dos custos de desistência (sunk cost $)^{52}$. A presença de sunk costs faz com que o indivíduo racional opte por um curso de ação que se ele pudesse voltar no tempo não teria escolhido, mas que ele o toma por já ter assumido anteriormente um compromisso.

2. Mises considera que toda escolha é comportamento propositado ou não se trata de escolha mas de reação automática a um estímulo. No entanto, a

methodological claims that may seem ludicrous initially become far less controversial once properly understood. To assert that there is but one scientific method, and that any analysis which does not conform to it is meaningless or dogmatic, is itself a dogmatic and unscientific attitude...".

52 Nozick (1977, p. 363): "It may be irrational to consider them, but people in restaurants, for example, whose food has come and turned out to be poor tasting certainly often speak as though the reason they're going ahead to eat it is that money already has been committed to it." 
fronteira entre escolha e comportamento automático não é tão nítida como ele sugere.$^{53} \mathrm{O}$ condicionamento simples (ou reflexo) detectado pelas experiências "pavlovianas" não seria considerado ação pela praxeologia de Mises. ${ }^{54}$ Mas o que dizer do "comportamento operante"? Sabemos que processos de condicionamento operante por uso de recompensas e punição (reforço positivo e negativo) aumentam ou diminuem a probabilidade de vários comportamentos e introduzem vários padrões de extinção. ${ }^{55}$ Os "behavioristas" aplicam seus princípios a vários tipos de comportamento que a praxeologia chamaria de ação propositada. Portanto, a fronteira entre ação e comportamento automático é borrada, problematizando o significado da categoria austríaca de ação.

Um outro bom exemplo de crítica internalista aparece em Barrota (1996). Ele argumenta que mesmo que o axioma da ação racional pudesse ser aceito haveria outros problemas na praxeologia de Mises:

1. O conceito de ação, junto com o conceito correlato de "tempo real", pode não ser a única premissa do modelo explicativo da praxeologia.

2. Modelos econômicos mutuamente incompatíveis podem ser derivados do conceito miseano de ação.

3. Pode ser que existam diferentes sistemas de categorias para um mesmo fenômeno.

Barrota explica que, embora Mises tenha herdado de Kant a preocupação com a construção e análise de categorias teóricas, ele não entendeu a sua função e tentou equivocadamente basear nela toda uma ciência dedutiva. ${ }^{56} \mathrm{Um}$ sistema de categorias leva a um conjunto de procedimentos dedutivos de modo a se derivar dele um leque de proposições econômicas significativas. Mas há a questão preliminar da escolha deste sistema entre duas ou mais possibilidades. Mises utiliza apenas a introspecção para justificar e validar a categoria da ação, mas mesmo que tal procedimento pudesse ser aceito, isto é, mesmo que a introspecção pudesse fornecer indubitavelmente um conhecimento a priori, ela não poderia descartar o uso de um outro sistema de categorias. ${ }^{57}$

\footnotetext{
${ }^{53}$ Conforme já comentamos no cap. 3, Mises estava ciente destas dificuldades, embora ele tenha evitado explorá-las.

${ }^{54}$ Por exemplo, a salivação de um animal com o toque da campainha.

55 Para Nozick (idem): "There is behavior which is not action; for example, simple unconditioned reflexes. By training, such behavior might come under the control of choice, but if such training didn't take place, the reflex behavior wasn't action (though the earlier 'nontraining' may have been)."

${ }^{56}$ Para Kant, Segundo Barrota (1996, p.59) as categorias servem para determinar o fenômeno da ciência: "the category of action, understood as 'conscious choice', does not supply the explanations of economic phenomena, but the very subject matter of economic explanations (and indeed of most human sciences)."

${ }^{57}$ Barrota (1996, p.60) cita como Sistema alternativo os conceitos de "produção" e "reprodução" da economia de M. Hollis e E. Nell.
} 
Poderíamos pensar em outros aspectos problemáticos na epistemologia de Mises, mas não queremos aqui esgotar tudo o que poderia ser dito. O mais importante é assinalar que as críticas internas são bem mais eficazes na identificação de deficiências na contribuição do austríaco. Além disso, tal crítica pressupõe um sério esforço preliminar de estudo e interpretação da sua obra. É necessário localizar a origem e a natureza de suas reflexões, pensá-lo como um autêntico herdeiro do movimento neokantiano. Para tanto, não precisamos nutrir algum tipo de afinidade ou simpatia. Mises é sempre um excelente mote para um exercício em história das ideias, um importante estudo de caso sobre uma epistemologia sui generis.

\section{REFERÊNCIAS BIBLIOGRÁFICAS}

BARONE, Enrico (s.d.); “The Ministry of Production in the Collectivist State”. In: F.A. Hayek (ed.) Collectivist Economic Planning, New York, Augustus M. Kelley.

BARROTA, Pierluigi (1996) “A Neo-kantian Critique of von Mises’s Epistemology”, Economics and Philosophy, 12.

BARROTA, Pierluigi. (1998) "Parsons on Mises and Kant: a Comment", Economics and Philosophy, 14

CALDWELL, Bruce J. (1984) "Praxeology and its Critics: an Appraisal”, History of Political Economy, $16,3$.

CALDWELL, Bruce J. (1986) “Towards a Broader Conception of Criticism”, History of Political Economy, $18,4$.

CRAVER, Earlene (1986) “ The Emigration of the Austrian Economists”, History of Political Economy, $18,1$.

ELSTER, Jon (1989a) “Social Norms and Economic Theory”, Journal of Economic Perspectives, vol. 3, 4. ELSTER, Jon. (1989b) The Cement of Society: a Study of Social Order, Cambridge.

HAYEK, F. A. (1968) “The Austrian School”, in Sills, D. L. (ed.) International Encyclopedia of the Social Sciences, vol. IV, New York: Macmillan and Free Press.

HENNIS, Wilhelm (1987) “A Science of Man: Max Weber and the Political Economy of the German Historical School”, in: Mommsen, W.J. and Osterhammel, J. (eds.) Max Weber and His Contemporaries, London, Allen \& Unwin.

HIRSCH, Abraham (1986), "Caldwell on Praxeology and its critics: a reappraisal”, History of Pulitical Economy. 18, 4.

HUTCHISON, Terence W. (1953) A Review of Economic Doctrines 1870- 1929, Oxford.

HUTCHISON, Terence W. (1981) The Politics and Philosophy of Economics: Marxists, Keynesians and Austrians, Oxford, Blackwell.

JOHNSTON, Willian M. (1983) The Austrian Mind, University of Chicago Press.

KAUDER, Emil (1957) “Intellectual and Polítical Roots of the Older Austrian School”, Zeitschrift für Nationalókonomie, 17.

KEIZER, W. (1989) “ Recent Reinterpretations of the Socialist Calculation Debate”, Journal of Economic Studies, 16, 2.

KIRZNER, Israel I. M. (1981) "Mises and the Renaissance of Austrian Economics”, in John K. Andrews Jr (ed.), Homage to Mises, Hillsdale College Press, Hillsdale, Michigan.

KIRZNER, Israel I. M. (1986) "Ludwig von Mises and Friedrich von Hayek: The Modem Extension of Austrian Subjectivism”, in von Norbert Leser (ed.), Die Wiener Schule der Nationalokonomie, Wien, Koln, Graz: Hermano Bohlaus Nachf.

KIRZNER, Israel I. M.. (1987) “Austrian School of Economics”, in. Eatwell, M. Milgrave and P. Newmann (eds.), The New Palgrave, a Dictionary of Economics.

LANGE, Oscar (1936) "On the Economic theory of Socialism”, The Review of Economic Studies, 4, 1. 
MISES, L. von (1933), Die Grundprobleme der Nationalokonomie. Engl. Trans.: Epistemological Problems of Economics, New York and London, New York University Press, 1981.

MISES, L. von (1949) Human Action: A Treatise on Economics, New Haven, Yale University Press.

MISES, L. von.(1981) Socialism: An Economic and Sociological Analysis, Indianapolis, Liberty Press.

MENGER, Carl (1883) Untersuchungen über die Methode der Socialwissenschaften, und der politischen Oekonomie insbesondere, Engl. Trans.: Problems of Economics and Sociology, Urbana, University of Illinois Press, 1963.

NOZICK, R. (1977) “On Austrian Methodology”, Synthese, 36, 2.

PARSONS, Stephen D. (1990) "The Philosophical Roots of Modem Austrian Economics: past problems and future prospects", History of Political Economy, 22, 2.

PARSONS, Stephen D. (1997) "Mises, the A Priori, and the Foundations of Economics: a Qualified Defense", Economics and Philosophy, 13, 2.

RIZZO, Mario J. (1982) “Mises and Lakatos: a Reformulation of Austrian Methodology”, in Israel M. Kirzner (ed.), Method, Process and Austrian Economics, Lexington, Mass. and Toronto, D.C. Heath \& Co, Ch. 6.

ROBBINS, Lionel (1969) An Essay on the Nature and Significance of Economic Science, London, Macmillan Press.

ROTHBARD, Murray N. (1988) O Essencial Von Mises, Rio de Janeiro, Livraria José Olympio Editora.

STIGLER, George, J. (1950) "The development of Utility theory”, The Journal of Political Economy, 4, 18.

VINER, Jacob (1958) The Long View and the Short-Studies in Economic Theory and Policy, Illinois, The Free Press Glencoe.

WHITE, L.H. (1977) "Methodology of the Austrian School”, Center for Libertarian Studies, Occasional Paper Series, 1, March. Rev. and published as The Methodology of the Austrian School Economists, The Ludwig von Mises Institute of Auburn University, Auburn, Alabama, 1984. 